\title{
crianças e guerra: as balas perdidas!
}

\author{
anete abramowicz ${ }^{1}$ \\ universidade de são paulo \\ orcid id: https:/ / orcid.org/0000-0002-4714-3602
}

resumo

Este artigo constitui-se em um ensaio que busca responder quais crianças na contemporaneidade têm sido alvo e mortas "sem querer", "ao acaso", pelo Estado brasileiro. Para buscar entender o lugar das crianças nesta "guerra", este estudo apoia-se, entre outros autores, em Achille Mbembe, Maurizio Lazzarato e Peter Pál Pelbart. O texto, organizado em seis partes, utilizou-se dos conceitos de biopolítica, biopoder e necropolítica em um primeiro momento, procurando mostrar o tipo específico de poder exercido na contemporaneidade. Compreende-se o biopoder não somente como um conceito militar, da guerra ou da política, mas também vinculado a uma guerra "biológica", como sugere Lazzarato, contra os negros, contra algumas sexualidades, contra algumas mulheres e contra algumas crianças. Buscou-se mostrar de que maneira a construção da ideia universal de criança exclui as que não pertencem a esta representação - em geral, difundida incessantemente como sendo uma imagem única de criança. Esta difusão de criança única, universal faz-se por meio de inúmeras formas discursivas, audiovisuais, imagéticas etc. e, dessa forma, exclui as crianças negras e todas aquelas que fazem desviar, ou "fugir" à maneira hegemônica de representar, pensar e escrever sobre o que é uma criança. Por fim, constatou-se que as crianças mortas são negras e pobres, e busca-se mostrar a importância da participação política das crianças nas cenas sociais.

palavras-chave: criança negra; biopolítica; necropolítica; participação política.

\section{children and war: the stray bullets!}

abstract

This essay seeks to answer the questions of which children in the contemporary world have been targeted and killed "unintentionally" or "at random" by the Brazilian State. In order to understand the place of children in this "war" we rely on the work, among others, of Achille Mbembe, Maurizio Lazzarato and Peter Pál Pelbart. Our text is structured in six sections. First, we take up the concepts of biopolitics, biopower and necropolitics, in an attempt to specify the type of governmental power that is exercised nowadays. Biopower is understood, not only as a military or political concept, but also in relation to a "biological" war (Lazzarato, 2016) against blacks, against certain sexualities, against some women and against some children. We than show how the construction of the universal idea of "child" excludes children who do not belong to this representation, which is, in general, disseminated as being the only image of a child. This diffusion of a single, universal notion of "child" is made through countless discursive and audiovisual imagery, and excludes black children and all those who diverge from or "flee" the hegemonic way of representing, thinking and writing about what a child is. Finally, we verify that the dead children are black and poor and we demonstrate the importance of children's political participation in social life.

keywords: black child; biopolitics; necropolitics; political participation.

1Email: aneteabramo@gmail.com 


\section{niños y guerra: las balas perdidas!}

resumen

Este artículo es un ensayo que busca responder qué niños, en el mundo contemporâneo, han sido atacados y asesinados "involuntariamente", "al azar" por el Estado brasileño. Para tratar de comprender el lugar de los niños en esta "guerra", nos apoyamos, entre otros, en: Achille Mbembe, Maurizio Lazzarato y Peter Pál Pelbart. La construcción del texto se llevó a cabo en seis partes. Los conceptos de biopolítica, biopoder y necropolítica se utilizaron al principio, tratando de mostrar el tipo específico de poder que se ejerce en los tiempos contemporáneos. El biopoder se entendió no solo como un concepto militar, de guerra o político, sino también en relación con una guerra "biológica" (Lazzarato, 2016), contra los negros, contra algunas sexualidades, contra algunas mujeres y contra algunos niños. Intentamos mostrar cómo la construcción de la idea universal de un niño excluye a niños que no pertenecen a esta representación, en general, diseminados sin cesar como una imagen única de niño. Esta difusión de un niño único y universal se realiza a través de innumerables formas discursivas, audiovisuales, imágenes, etc., y de esta manera excluye a los niños negros y a todos aquellos que se desvían o "escapan" de la forma hegemónica de representar, pensar y escribir sobre qué es un niño. Finalmente, verificamos que los niños muertos son negros y pobres y buscamos mostrar la importancia de la participación política de niños en las escenas sociales.

palavras clave: niño negro; biopolítica; necropolítica; participación política. 
crianças e guerra: as balas perdidas!

\section{1. biopoder}

Este é um ensaio sobre a questão dos direitos das crianças na perspectiva das relações raciais, ao mesmo tempo em que procura analisar por que determinadas crianças são mortas pelo Estado, mesmo que "ao acaso". Procurou-se neste artigo tensionar sobre o que são os direitos das crianças, em uma atmosfera social na qual o Estado decide quem deve morrer e executa crianças, dizendo ser "ao acaso", "sem querer", "balas perdidas" ou consequência de uma guerra "contra o tráfico", quando, de fato, trava uma guerra contra a população. Mas não contra toda a população. A hipótese levantada por este ensaio é que são mortas as crianças que não fazem parte daquilo que foi construído e inventado como "a criança universal" - o artigo $a$ denota esta ideia universal e unificadora.

Achille Mbembe, historiador camaronês, alcunhou esta prática política de necropolítica, conceito que se torna analítico neste texto. É uma biopolítica contemporânea, o biopoder: "aquele domínio da vida sobre o qual o poder tomou o controle" (Mbembe, 2016, p.123). O termo "biopolítica" apareceu na obra de Michel Foucault (1984) na conferência proferida no Rio de Janeiro em 1974, intitulada "O nascimento da medicina social". Segundo Pelbart (2019, p. 55),

dois anos depois, reencontramos a mesma expressão num contexto mais amplo, tanto no último capítulo de $A$ vontade de saber, publicado em 1976, como na aula ministrada no Collège de France em março do mesmo ano, publicada posteriormente como Em defesa da sociedade.

Achille Mbembe (2016) cunhou o termo necropolítica, uma política que extermina a vida, e o nazismo foi seu exemplo extremo. Segundo Mbembe (2016, p.146) ao propor

a noção de necropolítica e necropoder para explicar as várias maneiras pelas quais, em nosso mundo contemporâneo, armas de fogo são implantadas no interesse da destruição máxima de pessoas e da criação de "mundos de morte", formas novas e únicas da existência social, nas quais vastas populações são submetidas a condições de vida que lhes conferem o status de "mortos-vivos".

Nesta política a que assistimos hoje, em que o Estado "atira na cabeça das pessoas ${ }^{2 \prime \prime}$, pergunta-se: qual o lugar das crianças nesta guerra? Importante reter que

\footnotetext{
2 Em novembro de 2018, o governador eleito pelo Rio de Janeiro: Wilson Witzel afirmou "A polícia vai fazer o correto: vai mirar na cabecinha e... fogo! Para não ter erro" (Veja, 2018).
} 
o conceito da biopolítica, do biopoder não é um conceito militar, da guerra ou da política somente, mas implica, também, relação com uma guerra "biológica” (Alliez; Lazzarato, 2016). O que travamos hoje no Brasil, com a ascensão da extrema direita, é uma guerra "biológica", racial; uma guerra contra as mulheres. E precisamos entender a natureza da guerra contra as crianças que têm sido mortas.

\section{2. guerra}

Não há como falar de infância e de direitos das crianças, sem mencionar inicialmente os nomes Jenifer Gomes, Kavan Peixoto, Kauã Rosário Gomes, Kauê dos Santos e, mais recentemente, Ana Carolina de Souza Neves, primeira criança morta vítima de bala perdida no Rio de Janeiro em 2020, e de Ágatha Félix, entre muitas outras crianças mortas pelo Estado. Mortas pela política assassina, imposta no Brasil, que podemos denominar de "necropolítica", termo cunhado por Mbembe - pensador contemporâneo camaronês, professor de história na África do Sul. É a política da morte adotada pelo Estado, cujo alvo preferencial são as negras e os negros e os lgbti+ - é neste sentido que o biopoder opera na "biologia", na subjetividade.

Mas isto não começou agora.

No livro: A trégua, Primo Levi conta o seguinte episódio. Finda a guerra, quando voltava para a casa saído de Auschwitz, discute com um sobrevivente grego sobre o que importa mais durante a guerra, sapatos ou comida? O grego argumenta sapatos, pois "quem tem sapatos pode ir buscar comida, ao passo que o inverso não funciona". Mas a guerra já terminou retruca Levi, ao que o interlocutor responde: "Guerra é sempre". (Pelbart, 2019, p.9)

A guerra é agora. Parece paz, mas é guerra. Mbembe mostra, de maneira avassaladora em seu livro, que o horror do holocausto - imposto aos europeus, a judeus e judias, a ciganos e ciganas, a comunistas e homossexuais - causou um incessante assombro (não há palavras à altura para designar tal acontecimento, como dizia Primo Levi) e foi narrado de muitas maneiras, embora todas insuficientes. Mbembe ainda reporta que este assombro e este acontecimento narrados pelas artes e pela filosofia, em especial, foram motivados não só, evidentemente, porque os mortos eram brancos e europeus que estavam sendo sacrificados por uma máquina de morte promovida pelo Estado. O terror da 
escravidão, por exemplo, não gerou - nem mesmo após sua extinção - sequer uma pequena declaração de proteção às crianças, e a primeira declaração de proteção a elas veio após a Primeira Guerra Mundial, com a Declaração de Genebra sobre os direitos da Criança, sancionada pela Sociedade das Nações, predecessora da atual da ONU, em $1924^{3}$.

Mas o esquecimento, a morte e a tentativa de apagamento e invisibilização dos negros e das negras se dão mesmo quando se fala de morte, pois eles e elas são esquecidos(as), e este é um entre os muitos aspectos apontados no livro de Mbembe (2016), embora o debate central ali seja a questão da Palestina que, segundo o autor, pratica a forma mais bem-sucedida de necropoder e de ocupação colonial. Ainda sobre a necropolítica, ele descreve que não há capitalismo sem a escravidão negra e, portanto, o racismo estrutura o capitalismo. Mbembe mostra, então, que no DNA do capitalismo está a escravidão negra, embora - diz ele - na história humana sempre tivesse havido escravidão, mas nunca por causa da cor da pele. Negro, em Mbembe (2018, p. 21), é

\begin{abstract}
produto de um maquinário social e técnico indissociável do capitalismo, de sua emergência e globalização, esse termo foi inventado para significar exclusão, embrutecimento e degradação, ou seja, um limite sempre conjurado e abominado. Humilhado e profundamente desonrado, o negro é, na ordem da modernidade, o único de todos os humanos cuja carne foi transformada em coisa e o espírito em mercadoria - a cripta viva do capital.
\end{abstract}

\title{
3. senhor e escravo
}

Há outros esquecimentos dos negros e das negras, e há os esquecimentos e a invisibilização das epistemologias também.

Quando Hegel construía sua dialética, como nos mostra Susan Buck-Morss (2011) na obra Hegel e o Haiti, ele cometia uma discrepância gritante entre pensamento e prática, pois sabia da guerra dos escravos do Haiti, a maior revolução libertária da modernidade, porém a ignorou e preferiu construir um escravo abstrato. Não obstante, na história ocidental estudamos a Revolução Francesa e desprezamos a revolução do Haiti, que de fato é a primeira revolução moderna e

\footnotetext{
${ }^{3}$ Em 1848 teve lugar a primeira convenção dos direitos das mulheres.
} 
libertária, e a dialética senhor $\mathrm{x}$ escravo nada nos disse sobre o movimento de libertação dos escravos do Haiti.

Em algumas das faculdades de Educação, quando se estuda Paulo Freire falase do oprimido na chave hegeliana e do seu humanismo cristão, mas o oprimido de Paulo Freire não é outro senão aquele retratado no livro Os condenados da terra, de Frantz Fanon, a chave proposta por Freire para a leitura do oprimido. Num sobrevoo pela literatura mais ampla, é possível encontrar autores que vêm conectando Paulo Freire a uma dupla referência: o hegelianismo e o póscolonialismo.

Em relação ao segundo, é já notório o quanto o próprio Paulo Freire atribui a Frantz Fanon e a Albert Memmi uma série de inspirações fundamentais para seu pensamento. Em relação ao primeiro, não encontramos debate feito de modo mais extenso, embora exista, na própria obra de Freire, um longo flerte com Hegel. (Munari, 2017, p. 59)

As $\operatorname{cotas}^{4}$ deveriam significar não só a entrada de negras e negros nas universidades, mas também a entrada de uma outra epistemologia, pois a universidade se erige na branquitude na maioria dos seus referenciais $\mathrm{e}$ epistemologias. Foi isto que nos indicou, por exemplo, a excelente mostra artística da pós-colonialista Greda Kilomba, na Pinacoteca do Estado de São Paulo ${ }^{5}$, ao mostrar o patriarcado que se erige na concepção do Édipo, por exemplo. O Brasil, em seu DNA social, na construção do perverso capitalismo brasileiro, tem sangue negro e nos estrutura como uma sociedade racista. Como disse Nilma Lino Gomes (2017), as placas tectônicas de formação do Brasil são racistas, e sobre elas nos subjetivamos. E tal é a violência deste governo de extrema direita contra todas as pautas da diferença que nos são caras, porque, de alguma maneira, mexemos nestas

\footnotetext{
${ }^{4}$ No Brasil, o sistema de cotas tornou-se conhecido em meados dos anos 2000, inicialmente pela Universidade do Estado do Rio de Janeiro (UERJ), que foi a primeira universidade do País a criar um sistema de cotas em vestibulares para cursos de graduação por meio de uma lei estadual que estabelecia $50 \%$ das vagas do processo seletivo para alunos egressos de escolas públicas cariocas. Regulamentada pelo Decreto n. $.^{\circ} 7.824 / 2012$, essa lei propõe $25 \%$ das vagas para estudantes oriundos da rede pública com renda igual ou inferior a 1,5 salários mínimos, 25\% para candidatos que estudaram integralmente no ensino médio e que possuem renda igual ou superior a 1,5 salários mínimos e, ainda, um percentual para pretos, pardos e indígenas, conforme o último Censo Demográfico do Instituto Brasileiro de Geografia e Estatística (IBGE) na região.

5 Grada Kilomba, com raízes em São Tomé e Príncipe, Angola e Portugal, atualmente vivendo e trabalhando em Berlim, teve uma exposição denominada: "Desobediências Poéticas", realizada de 6 de julho a novembro de 2019 na Pinacoteca do Estado de São Paulo.
} 
placas. O que mostra que estávamos certos: a diferença tem um potencial disruptivo em que temos que investir.

\section{4. criança negra}

Voltemos às crianças. Algo mudou na história para que a criança emergisse de uma certa forma. Algo mudou, e a criança emergiu. Na linha desse pensamento, uma forma não tem uma origem, mas tem uma emergência; e, se as forças mudam, a forma muda. Se não há forma imutável, significa que a criança muda sempre e pode, inclusive, desaparecer. É isso que dizia Philippe Ariès (1978), essa 'forma' criança foi mudando ao longo da história (Abramowicz, 2018). Michel Foucault (1979) interessou-se pelo problema daquilo que se diferencia na história, e a criança é algo que emerge, pois uma diferença foi produzida. Nesse percurso epistemológico, portanto, tudo é histórico, pois tudo emerge. Se essa forma é construída pelas relações de forças, ela é disputada. Por isso, quando o movimento negro afirma que é preciso representar crianças negras, é porque a ideia de criança emerge de uma determinada forma, com uma cor, com certos trajes, etc., e essa forma exclui a criança negra e outras mais.

Não há ilusões, o direito das crianças não é para todas! A própria emergência da criança na atmosfera científica ocidental despontou com uma cor, com uma estética, com uma religião, com atributos "naturais" como o brincar, por exemplo que criança é esta? Há que se disputar a própria ideia de criança, pois em nome dela estão sendo fechados os museus e a arte, censurada; o campo do possível pouco a pouco vai sendo vedado.

Esta ideia de criança que emergiu condiciona e constrói uma imagem de pensamento e foi fruto de disputas de muitas forças: epistemológicas, teológicas, pedagógicas, filosóficas. E, quando tal forma de criança emerge, há uma construção que se faz hegemônica, que lhe imprimiu uma cor, um jeito de ser, uma forma e conteúdos construídos sob a denominação de "natureza humana" - na qual supostamente alguns se (re)conhecem em alguns valores que se imprimem na criança, entre eles a bondade, a ingenuidade, a pureza... Imenso o esforço para preencher subjetivamente esta forma criança, ao ponto de, quando vemos Ágatha, 
seu avô, aos berros, tenta nos dizer: "Ela fala inglês, tem aula de balé, tem aula de tudo, era estudiosa. Ela não vivia na rua, não" (Carvalho, 2019). Ágatha vestia-se de mulher maravilha (que tem a bandeira americana estampada em sua roupa, em sua pele). O que ele tentava dizer era: minha neta vai exatamente ao encontro desta imagem que o pensamento ocidental faz de criança. Desnecessário dizer que não se chorou sua morte da mesma maneira que se choram as mortes das crianças ricas e brancas, e não se chorou o suficiente.

Butler (2015) diz sobre as vidas que não são choradas igualmente, sobre a distribuição desigual da precariedade da vida. Nenhuma declaração do presidente, pois Agatha não faz parte do imaginário hegemônico de criança construído tão minuciosamente e micropoliticamente por teólogos, pedagogos, juristas e supostos defensores da família e das crianças, etc. Portanto, não podemos falar de crianças abstratas e de direitos das crianças - para não cometer, guardadas as devidas proporções, o erro de Hegel: falar de uma abstração de direitos -, sem falar das crianças concretas e mortas no Brasil. Em especial crianças e jovens negros e negras, porque, com a morte de pretos e pretas, a indignação é menor! Há no Brasil uma política de governamento desta população, sobretudo negra e pobre, que é o encarceramento em massa, de um lado; e, de outro, as escolas lotadas e precarizadas. Não há como escapar da luta pelo abolicionismo penal!

\section{5. "filantropização" das creches}

A infância, a educação infantil e o direito das crianças não estão fora desse movimento de ataque e desse retrocesso, sobre o qual devemos afirmar também que não começou hoje. As crianças de zero a 3 anos estão pouco a pouco fazendo parte do processo que chamamos de "filantropização ${ }^{6 "}$ da infância, que significa passar os bebês e as crianças de até 3 anos para as entidades filantrópicas, sobretudo religiosas. Primeiro há que se dizer que os direitos das crianças e a defesa de uma infância sempre foram terrenos de disputas. As crianças são objetos permanentes

\footnotetext{
6 Pesquisas nacionais recentes vêm indicando que os municípios sob pressão para cumprimento da Lei 12.796/2013, que prevê a obrigatoriedade de atendimento a crianças de 4 e 5 anos por parte do poder público municipal, tentam encontrar formas alternativas para suprir tal demanda, como a ampliação do atendimento de creches por meio de convênios, muitos deles com entidades religiosas, uma tendência que temos chamado de "filantropização" das creches (OBEDUC, 2018).
} 
da biopolítica, que é o controle e o governamento da população, pois não há território e corpo mais fugidios do que os das crianças, e mais disputados para atribuir-lhes uma essência e subjetividade. É preciso operar incessantemente sobre eles; e se opera, efetivamente, todo o tempo sobre eles, sobre os corpos das crianças e seus territórios - desse modo, as ordens religiosas têm colocado as crianças pequenas aos seus encargos.

A história da criança é a história do horror, da morte, da pobreza, da miséria, do trabalho, do infanticídio, pois elas estão totalmente à mercê do mundo dos adultos, um mundo adultocêntrico; e, por vezes, aqueles e aquelas que as protegem - seus pais, os adultos, o Estado - também as destroem. Uma das mais radicais feministas, um pouco esquecida entre nós, Shulamit Firestone (1970, p.87), em A dialética do sexo, no capítulo denominado "Abaixo a infância", discorre sobre a opressão das mulheres e das crianças. Diz ela que "sempre são mencionadas simultaneamente": “Mulheres e crianças para trás!”, e ainda afirma sobre a natureza opressiva desta relação e a necessidade de as crianças se libertarem de suas mães. E escreve isto entre 1968 e 1970! Elias Canetti, em seu livro Massa e poder (1983), também segue um pouco este caminho dizendo, já em 19607, quando da primeira edição desta obra, do quanto as mães impõem um paladar às crianças. O que é então ser pesquisador(a) e militante das causas das crianças exatamente neste momento, para aquelas e aqueles que se propõem a estar nas lutas e com as crianças?

\section{6. participação política das crianças}

O que tem sido esta justiça brasileira que o sociólogo André Singer (VI O MUNDO, 2018) tem chamado de Partido da Justiça? É a maneira pela qual o estado burguês ganha a aparência de justo. Foucault (1977, 1984, 1987) disse incansavelmente, em suas pesquisas e pensamento, que a justiça é tudo o que a burguesia quer e precisa para impor seus valores, suas crenças, suas opiniões, de forma legitimada e pacífica. Por isso é que a justiça se impõe sempre para os pobres, porque é feita para eles aceitarem as imposições da lógica do capital. Judicializou-

\footnotetext{
${ }^{7}$ Masse und Macht. Claassen, Hamburg 1960.
} 
se a diversidade desde o golpe ${ }^{8}$, o que significa que tentam reinscrevê-la, reduzi-la, sufocá-la, a partir da escola sem partidos, da chamada ideologia de gênero, etc. Não há base para a criação de uma justiça universal, então a justiça é, na verdade, uma posição política sobreposta aos que não aderem.

É preciso dizer de maneira clara: Estamos em guerra! Estamos em guerra, de um modo singular, em que guerra e paz se confundem - parece que estamos em paz, mas é guerra. Faço uma citação um pouco longa, mas vale a pena:

O filósofo Peter Pál Pelbart (2019a, [s.p.]) afirma:

Vivemos uma regressão a passos de gigantes, inversão dos valores, o crime é chamado de segurança, a perseguição de justiça, o genocídio de pacificação, a destruição é chamada de salvação, o ódio de patriotismo, a guerra de paz e eu acrescento a universidade de balbúrdia. Diante de um revanchismo sanguinário e a sede de vingança avassaladora contra tudo do que nos é caro, cresce em nós a cada dia a vergonha e a desolação.

Ele continua:

A linguagem perdeu sua eficácia, os sentidos foram virados do avesso, as palavras foram arrastadas para uma inefetividade, como se não se importasse em absoluto o que se diz, o que se escreve, o que significa, um certo esvaziamento do pensamento. Privados das palavras do corpo da vida vivemos a depauperação da experiência do que nos falava Walter Benjamin, quando mostrou que diante da guerra e da fome e da humilhação, ficamos mais pobres do que antes de experiências comunicáveis, não mais ricos. Não estamos diante da guerra, inflação, humilhação, pobreza tal como os combatentes de 1914, mas é necessário hoje em dia uma prova de honradez confessar nossa pobreza, o depauperamento da linguagem, o esvaziamento das relações nada constitui uma fatalidade existencial, intrínseca à natureza humana, que constatamos agora ser o pão nosso de cada dia. O que está em jogo é uma forma de vida depauperada. Nós topamos o depauperamento e é contra isto que temos que lutar entre nós.

E as crianças?

Godard dizia que as crianças eram prisioneiras políticas. “As crianças são prisioneiras políticas", dizia Godard, mas são prisioneiras de prisioneiros, porque os adultos, por maioria de razão, também são prisioneiros políticos. As crianças acompanham seus pais, solidárias que são nas travessias das mais perigosas, como

\footnotetext{
${ }^{8}$ Em 31 de agosto de 2016, Dilma Rousseff perdeu o cargo de Presidente da República após três meses de tramitação do processo iniciado no Senado, que culminou com uma votação em plenário resultando em 61 votos a favor e 20 contra o impedimento. Acusada de praticar uma manobra contábil, que compôs as chamadas "pedaladas fiscais", mas nem esta prática foi comprovada.
} 
no Mediterrâneo em direção à Europa, ou mesmo nas travessias do Atlântico, seja saindo da África ou do Oriente Médio. Acompanham seus pais nas ocupações de terras e prédios no Brasil, acompanham seus pais ou os adultos nos corredores e nas esquinas das cidades, fazendo malabarismo ou pedindo dinheiro, buscando extrair alguma empatia dos adultos. As crianças se lançam nestas jornadas, não sabem nadar quando se lançam ao mar, e estão à mercê das forças econômicas, raciais, étnicas, etc. de destruição, além das questões vinculadas ao recorte etário, pois, em quaisquer destas circunstâncias, dependem totalmente dos adultos. Assim: a questão política significa pensar que aparatos e dispositivos podemos criar para proteger a criança da gana do capital, do racismo, das discriminações, da pobreza, dos jogos eletrônicos, etc.?

Pesquisar crianças é estar com elas, é buscar aceder a seu desejo, no sentido de buscar uma perspectiva que alcance as suas perspectivas. Ou seja, qual ponto de vista adotar para buscar o ponto de vista das crianças? Podemos complexificar tudo isto, ao agregar, a esta formulação, Guattari, que em 1981(1 $1^{\mathrm{a}}$ edição) colocou a questão ainda contemporânea: "como evitar que as crianças se prendam às semióticas dominantes ao ponto de perder muito cedo toda e qualquer verdadeira liberdade de expressão"? (Guattari, 1985, p. 50). São duas das questões fundamentais que as pesquisas devem responder para aqueles(as) que pretendem estar ao lado das crianças e buscar saber o que afeta as crianças e os bebês.

Como buscar esta perspectiva, sabendo que todos os dispositivos de saber e poder são adultocêntricos e que reservam um lugar específico e menor para as crianças, em todas e quaisquer das hierarquias sociais, das discursivas às não discursivas. As crianças estão confinadas às casas, mesmo que o que se passa ali, no privado, tenha um caráter político e público. E querem mantê-las cada vez mais prisioneiras em suas casas - é a proposta de homeschooling. Assim como a mulher é designada às casas para cuidar de seus filhos, seu corpo também é disputado, como diagramaram largamente as feministas desde Simone de Beauvoir, Shulamith Firestone a Judith Butler e Paul B. Preciado, mostrando que desde o início a casa é, por excelência, um espaço público, na medida em que é o lugar em que as mulheres 
são subjetivadas, como tendo o lugar "próprio" delas, "as mulheres do lar", e o lugar das crianças cuidadas e assistidas e desprovidas de falas, desejos etc.

Quais ferramentas teóricas e metodológicas temos à disposição e de qual cardápio analítico dispomos para procurar responder às questões postas?

Buscar a perspectiva das crianças é uma tarefa analítica das mais difíceis. Os sociólogos da infância incansavelmente têm afirmado que a participação política da criança, bem como sua fala, envolve essencialmente cenas políticas dissonantes das hegemonias discursivas e participativas, que dão como natural que tais ações devam ser realizadas pelos adultos. A criança falar, participar das cenas sociais como agente destes processos insere-se em uma das mais eficazes lutas micropolíticas - é uma espécie de movimento político, pois a escola, em especial, está orientada para a conformação política da criança e é incapaz de escutá-la.

Angela Davis nos coloca exatamente a questão fundamental sobre o que é a participação das crianças nas lutas contra o racismo e sobre a discriminação na luta contra o fascismo, por exemplo: Diz ela:

Lembro que, em 1963, durante a época da luta pelos direitos civis, antes da Marcha sobre Washington, no verão daquele ano, houve uma cruzada infantil em Birmingham, Alabama. As crianças foram mobilizadas para enfrentar jatos d'água de alta potência e a polícia, que em Birmingham estava sob as ordens de Bull Connor. Óbvio que algumas pessoas não concordaram em permitir que as crianças tivessem tal grau de participação - mesmo Malcom X pensava que não era apropriado expô-las a tamanho perigo -, mas elas quiseram participar. E as imagens das crianças fazendo frente aos cães da polícia e aos jatos d'água circularam por todo o mundo, ajudando a criar uma conscientização global sobre a brutalidade do racismo. Foi uma iniciativa extraordinária. E esse papel que as crianças desempenharam para romper a barreira de silêncio em torno do racismo é algo com muita frequência esquecido. (Davis, 2018, p. 81)

A nossa perspectiva é pensar de que maneira a criança pode, ela própria, interrogar sua infância; de que maneira pode infletir, interrogar, subtrair e resistir à ideia de infância, quando ela se apresenta como um dispositivo fabricado e, de certa maneira, garantidor de um funcionamento da sociedade. $\mathrm{O}$ nosso desafio é empreender um esforço posto por Deleuze e Guattari, que concebem “a ideia de um adulto modulado pela criança, a ideia de que o homem precisa de devir criança para conseguir desfazer os modelos consensuais anteriores ao seu próprio pensamento" (Schérer, 2012, p. 66). Esta ideia é fabulosa, pois é a criança interrogando sua infância 
como uma possibilidade de resistir, como um poder da vida se opondo ao poder sobre a vida. A própria ideia de infância como aquela capaz de descolonizar a pesquisa com crianças. Deleuze em conversa com Foucault (1984, p. 72) dizia:

Se as crianças conseguissem que seus protestos, ou simplesmente suas sugestões fossem ouvidas em uma escola maternal, isto seria o bastante para fazer explodir o conjunto do sistema de ensino. $\mathrm{Na}$ verdade, esse sistema nada pode suportar: daí sua fragilidade radical em cada ponto, ao mesmo tempo em que sua força global de repressão.

A questão é que há uma infância que modela a criança. E quem concebe a infância é o adulto, que a pensa de maneira pregressa e assim retira a potência e a possibilidade de transformação que há na própria infância. A criança está empobrecida no aluno, no pequeno consumidor, empobrecida em ideias preconcebidas de infância. Como fazer a criança falar - isto não é pouca coisa. Como conseguir romper com a grade ostensiva e poderosa daqueles que falam e têm suas falas consideradas, e todas as outras não o são? Como fazer ecoar as vozes que não ressoam, ou, como diz Walter Benjamim (1996), as vidas que não deixam rastros? Há que restabelecer as distribuições de posição, de lugar e de poder entre adultos e crianças, de maneira a emancipar e dar autonomia às crianças, e, segundo René Schérer (2012, p. 65), "pensar uma infância maior, emancipada, infantil, mas não infantilizada". Deste modo, importa indicar, há uma infância que surge, sempre há uma infância que surge - mesmo quando nada indica que seja possível brotar algo deste e de outros tempos sombrios. São as infâncias que estes tempos tentam matar! Pois as infâncias são o outro do mundo! Se há uma nova possibilidade de reconstrução social, é na própria infância que temos que buscar.

“Não é concebível um pensamento crítico que não seja também, em quaisquer de suas facetas, uma meditação sobre a infância” (Virno, 2012, p. 34)

referências

Abramowicz, A. Panorama atual da Educação Infantil: suas temáticas e políticas. In: Abramowicz, A.; Canella, A. Educação Infantil: a luta pela infância. Campinas: Papirus, 2018.

Alliez, E.; Lazzarato, M. Guerres et capital. Paris: Éditions Amsterdam, 2016.

Ariès, Ph. História social da criança e da família. Tradução de D. Flaksman. Rio de Janeiro: LTC, 1978. (Trabalho original publicado em 1973).

Buck-Morss, S. Hegel e Haiti. Novos estud. - CEBRAP, São Paulo, n. 90, p. 131-171, jul. 2011. Disponível em: 
<http:/ / www.scielo.br/scielo.php?script=sci_arttext\&pid=S010133002011000200010\&lng=en\&nrm=iso>. Acesso em: 08 fev. 2020. http:/ / dx.doi.org/10.1590/S0101-33002011000200010.

Butler, J. Vie précaire. Les pouvoirs du deuil et de la violence. Paris: Éditions Amsterdam, 2015. Caneti, E. Massa e poder. Brasília: Editora da UNB, 1983.

Carvalho, Edu. Como explicar a morte de Ágatha para uma criança? Folha de S. Paulo, 1 out. 2019. Cotidiano. Disponível em: https://www1.folha.uol.com.br/cotidiano/2019/10/como-explicar-a-morte-deagatha-para-uma-crianca.shtml Acesso em: 01/10/2019.

Davis, A. A liberdade é uma luta constante. São Paulo: Boitempo, 2018.

Firestone, Sh. The dialectic of sex: The case for feminist revolution. New York: William Morrow and Company, 1970.

Foucault, M. História da sexualidade - A vontade de saber. 3. ed. Rio de Janeiro: Graal, 1977. v. 1.

Foucault, M. Nietzsche, a genealogia e a história. In: Foucault, M. Microfísica do poder. Rio de Janeiro, Graal, 1979.

Foucault, M. Microfísica do poder. Tradução de Roberto Machado. Rio de Janeiro: Graal, 1984.

Foucault, M. Vigiar e punir. São Paulo: Vozes, 1987.

Foucault, M. Em defesa da sociedade. Tradução de Maria Ermantina Galvão. São Paulo: Martins Fontes, 1999.

Gomes, N. L. O movimento negro educador: saberes construídos na luta por emancipação. Petrópolis: Vozes, 2017.

Guattari, F. Creches e a iniciação. In: Guattari, F. Revolução molecular: pulsações políticas do desejo. São Paulo: Brasiliense, 1985, $3^{\text {a }}$ edição.

Mbembe, A. Necropolítica. Arte \& Ensaios - Revista do PPGAV/EBA/UFRJ, n. 32, p. 123, dez. 2016.

Mbembe, A. A crítica da razão negra. São Paulo: N-1 Edições, 2018.

Munari, S. Linhas de errância: vidas precárias e Pedagogia. Tese (Doutorado) - Programa de Pós-Graduação em Educação, Universidade Federal de São Carlos - PPGE UFSCar, São Carlos, 2017.

Observatório Da Educação - OBEDUC. Políticas públicas municipais de Educação Infantil: diagnóstico e pesquisa. Brasília: OBEDUC/CAPES/INEP, 2018.

Pelbart, P. P. Palestra na PUC de São Paulo. 2019a. Disponível em: <https://drive.google.com/file/d/16FFWdF8SS51-gP5mZ6-1_F7FalkT8n3I/view.> Acesso em: 20/9/2019.

Pelbart, P. P. Ensaios do assombro. São Paulo: N-1 Edições, 2019 b.

Schérer, R. Devir-criança: devir-maior ou devir-menor. Conversa com René Schérer. In Imprópria. Política e pensamento crítico. N.2, 2012.

Veja. Wilson Witzel: “A polícia vai mirar na cabecinha e... fogo!”. Revista Veja, São Paulo, 1 nov. 2018. Política. Disponível em: <https://veja.abril.com.br/politica/wilson-witzela-policia-vai-mirar-na-cabecinha-e-fogo/> Acesso em: 01/11/2019.

Vi O Mundo. André Singer fala no avanço do Partido da Justiça. E coluna do Estadão mostra como ele atua para tirar Lula da política. 22 abr. 2018. Política. Disponível em: $<$ https://www.viomundo.com.br/politica/no-avanco-do-partido-da-justica-e-colunado-estadao-so-confirma-como-ele-atua-para-tirar-lula-da-politica.html.> Acesso em: 07/12/2019.

Virno, P. Infância e pensamento crítico. Imprópria: política e pensamento crítico, Lisboa, n. 2, 2012. 